Article

\title{
Contribution of Trunk Muscles to Upright Sitting with Segmental Support in Children with Spinal Cord Injury
}

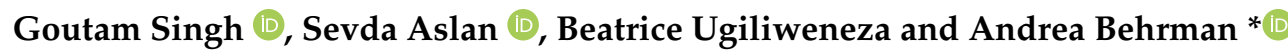 \\ Department of Neurological Surgery, University of Louisville, Louisville, KY 40202, USA; \\ goutam.singh@louisville.edu (G.S.); sevda.aslan@louisville.edu (S.A.); \\ beatrice.ugiliweneza@louisville.edu (B.U.) \\ * Correspondence: Andrea.behrman@louisville.edu; Tel.: +1-502-582-7451
}

Received: 16 November 2020; Accepted: 4 December 2020; Published: 8 December 2020

check for updates

\begin{abstract}
To investigate and compare trunk control and muscle activation during uncompensated sitting in children with and without spinal cord injury (SCI). Static sitting trunk control in ten typically developing (TD) children ( 5 females, 5 males, mean (SD) age of 6 (2)y) and 26 children with SCI (9 females, 17 males, 5(2)y) was assessed and compared using the Segmental Assessment of Trunk Control (SATCo) test while recording surface electromyography (EMG) from trunk muscles. The SCI group scored significantly lower on the SATCo compared to the TD group. The SCI group produced significantly higher thoracic-paraspinal activation at the lower-ribs, and, below-ribs support levels, and rectus-abdominus activation at below-ribs, pelvis, and no-support levels than the TD group. The SCI group produced significantly higher lumbar-paraspinal activation at inferior-scapula and no-support levels. Children with SCI demonstrated impaired trunk control with the ability to activate trunk muscles above and below the injury level.
\end{abstract}

Keywords: trunk muscle activation; spinal cord injury; children; surface electromyography

\section{Introduction}

Trunk muscles innervated by the thoracic and lumbar spinal nerves are critical for stability and mobility as they are involved in virtually all movements requiring an upright posture whether seated, standing, or walking [1-3]. The development of independent sitting is accomplished during the first year of life, as infants gradually learn to maintain their center of mass within the base of support. This is achieved by activating trunk muscles to hold the trunk upright during independent sitting and reaching tasks $[4,5]$. As children continue to develop, the activation and coordination of trunk muscles are required for more dynamic sitting and the transition to standing and walking [6,7]. Therefore, adequate trunk control in children is critical to participate in their environment.

Spinal cord injury (SCI) in children at cervical and upper thoracic cord levels results in paralysis or paresis of trunk muscles, as well as muscles of upper and lower extremities. As a consequence, children are unable to maintain an upright posture during sitting $[1,8,9]$. Compared to adults, paralysis of trunk muscles in children has an added complexity of on-going musculoskeletal growth through childhood and adolescence, placing children at greater risk for developing scoliosis [10,11]. The International Standards for Neurological Classification of Spinal Cord Injury (ISNCSCI) is used by therapists to assess the spinal cord motor and sensory function and then classify the severity of SCI [12] via the American Spinal Injury Association Impairment Scale (AIS). The scale, however, uses the outcomes of sensory perception with the patient tested in the supine position to indirectly assess the motor function of the trunk muscles [13,14]. The AIS scale is unreliable for assessing children under 
six years of age due to the inability to fully comprehend and follow instructions during the test [15]. Lack of appropriate tools to evaluate sitting trunk control has been a challenge for its assessment, particularly in children following SCI. Without such instruments, developing effective treatments and strategies also is difficult. Using surface electromyography (EMG) in a seated position, may be an effective alternative to the AIS to examine the activation of trunk muscles in adults, [16] adolescents, and children with SCI.

Tests such as the Trunk Impairment Scale and the Gross Motor Function Classification System have been used to measure trunk control in children and adults with neurological based impairments [17,18]. However, independent sitting and standing by participants is a prerequisite for these tests. Therefore, testing trunk control in children who have not achieved independent sitting and in children with a low functional level is limited [19]. In addition, these tests measure trunk performance as a single unit with trunk often collapsing in a " $\mathrm{c}$ " posture, i.e., compensation. A new pediatric, measurement instrument, the Segmental Assessment of Trunk Control (SATCo), was recently introduced and validated to assess and track improvements in trunk control in children with SCI lacking independent sitting or impaired sitting control [20]. The SATCo is based on observation of the natural acquisition of trunk control in typically developing (TD) children which occurs segmentally in a cephalocaudal direction and has been used in children with neuromuscular disorders [21]. The test uniquely assesses posture control in the sitting position with a stable, neutral base of pelvis controlled via straps or manually with support. External support is provided in a segmental manner at each biomechanical level: shoulders, axillae, inferior-scapulae, ribs, below-ribs, pelvis, and finally no-support while trunk control, above the external support, is evaluated for static, active, or reactive control. For evaluation of static control, a neutral vertical trunk position in the sagittal and frontal plane is held for five seconds as the individual maintain the head in midline [22].

We undertook this study as a critical step to understand the contribution of trunk muscles during upright sitting in children with SCI. The aim, thus, of this study was to examine and compare levels of trunk control per the SATCo and trunk muscle activation during uncompensated sitting in children with SCI to TD children. We selected to test children during the static control component, i.e., quiet sitting, while simultaneously recording trunk muscle activity. We hypothesized that children with SCI would show (a) significant deficits in trunk control measured by SATCo scores compared to age-matched TD children and (b) significantly lower or absent trunk muscle activation below the injury level at the same segmental support level compared to age-matched TD children.

\section{Materials and Methods}

\subsection{Participants and Clinical Characteristics}

The Institutional Review Board (IRB) at the University of Louisville approved this study (IRB protocol \#15.0585). Informed consent and assent were signed by legal guardians of participant and participant above 7 years of age, respectively. Ten TD participants ( 5 females and 5 males, age $6 \pm 2$ years) (Table 1) were recruited from the community. The Human Locomotion Research Center Database at the University of Louisville, Louisville, KY, USA (IRB approval \# 06.0647), was used to recruit twenty-six participants with chronic traumatic or non-traumatic SCI ( 9 females and 17 males, age $5 \pm 2$ years). The severity and level of SCI in children of 6 years of age or above were classified using the AIS by ISNCSCI and children below 6 years of age were classified as listed in their medical records. 
Table 1. Demographic characteristic of children with spinal cord injury and typically developing children.

\begin{tabular}{|c|c|c|c|c|c|c|c|c|}
\hline ID & Age (y) & Sex & BMI & $\begin{array}{l}\text { Injury/AIS } \\
\text { Level }\end{array}$ & $\begin{array}{l}\text { SATCo } \\
\text { Score }\end{array}$ & Injury Etiology & $\begin{array}{l}\text { Age at the } \\
\text { Injury (y) }\end{array}$ & $\begin{array}{c}\text { Time Since } \\
\text { Injury (y) }\end{array}$ \\
\hline A85 & 2 & $\mathrm{M}$ & 15.8 & $\mathrm{~T} 10$ & 19 & Epidural abscess & 1 & 2 \\
\hline P24 & 2 & $\mathrm{M}$ & 15.5 & C6-T6 & 11 & Epidural hematoma & 1.6 & 1 \\
\hline P33 & 2 & $\mathrm{M}$ & 18.4 & C3 & 8 & Neuroblastoma & 0 & 2 \\
\hline P39 & 2 & $\mathrm{~F}$ & 18.2 & $\mathrm{~T} 6$ & 12 & Neuroblastoma & 0.8 & 1.8 \\
\hline P12 & 3 & M & 14.1 & L1-2 & 12 & Cardiac infarction & 1.7 & 1.3 \\
\hline $\mathbf{P} 23$ & 3 & M & 13.9 & C4-C7 & 8 & Transverse Myelitis & 2.4 & 1 \\
\hline P34 & 3 & M & 17.5 & $\mathrm{~T} 4$ & 7 & Spinal astrocytoma & 1.2 & 2.2 \\
\hline P15 & 4 & $\mathrm{~F}$ & 15.0 & $\mathrm{~T} 12$ & 18 & Epidural abscess & 3 & 1 \\
\hline P22 & 4 & M & 15.5 & $\mathrm{~T} 4$ & 9 & $\begin{array}{l}\text { Motor vehicle } \\
\text { accident }\end{array}$ & 3.5 & 0.5 \\
\hline P3 & 4 & M & 16.1 & $\mathrm{~T} 2$ & 6 & Neuroblastoma & 0 & 4 \\
\hline P8 & 4 & F & 26.3 & $\mathrm{C} 2$ & 9 & $\begin{array}{l}\text { Motor vehicle } \\
\text { accident }\end{array}$ & 1.3 & 3.4 \\
\hline P14 & 5 & M & 15.4 & $\mathrm{C} 7$ & 9 & $\begin{array}{c}\text { Motor vehicle } \\
\text { accident }\end{array}$ & 3.5 & 2.3 \\
\hline P16 & 5 & M & 15.5 & $\mathrm{~T} 11$ & 18 & Pedestrian hit by car & 4 & 1 \\
\hline P25 & 5 & $\mathrm{~F}$ & 15.4 & $\mathrm{~T} 2$ & 14 & Spinal cord infarct & 4.2 & 1 \\
\hline P32 & 5 & $\mathrm{~F}$ & 18.0 & $\mathrm{~T} 2-\mathrm{T} 3$ & 14 & $\begin{array}{c}\text { Motor vehicle } \\
\text { accident }\end{array}$ & 3.3 & 1.4 \\
\hline P13 & 6 & M & 15.3 & T3A & 9 & $\begin{array}{l}\text { Motor vehicle } \\
\text { accident }\end{array}$ & 5.8 & 0.8 \\
\hline P20 & 6 & M & 25.1 & $\mathrm{~T} 10$ & 12 & $\begin{array}{l}\text { Motor vehicle } \\
\text { accident }\end{array}$ & 4.6 & 1.9 \\
\hline P4 & 6 & $\mathrm{~F}$ & 13.6 & C7-B & 9 & $\begin{array}{c}\text { Surgical } \\
\text { complication }\end{array}$ & 6.4 & 0.3 \\
\hline P40 & 6 & M & 16.8 & C2-D & 9 & $\begin{array}{l}\text { Motor vehicle } \\
\text { accident }\end{array}$ & 4.7 & 1.7 \\
\hline P7 & 6 & $\mathrm{~F}$ & 15.3 & $\mathrm{C} 4-\mathrm{C}$ & 9 & Fall & 3.5 & 2.5 \\
\hline P21 & 7 & $\mathrm{~F}$ & 13.5 & T10-A & 17 & $\begin{array}{l}\text { Performing } \\
\text { backbend }\end{array}$ & 5.6 & 1.8 \\
\hline P6 & 7 & M & 15.5 & T8-A & 10 & $\begin{array}{l}\text { Motor vehicle } \\
\text { accident }\end{array}$ & 4.4 & 3.5 \\
\hline P9 & 7 & F & 17.7 & $\mathrm{~T} 2-\mathrm{B}$ & 11 & $\begin{array}{l}\text { Motor vehicle } \\
\text { accident }\end{array}$ & 4 & 2.5 \\
\hline P1 & 9 & $\mathrm{M}$ & 14.6 & T1-B & 6 & Epidural hematoma & 4.2 & 4.6 \\
\hline P10 & 9 & M & 15.3 & $\mathrm{C} 5-\mathrm{C}$ & 12 & Transverse Myelitis & 0.4 & 8.9 \\
\hline P30 & 13 & M & 16.2 & C5-A & 4 & $\begin{array}{c}\text { Motor vehicle } \\
\text { accident }\end{array}$ & 2 & 11 \\
\hline $\begin{array}{l}\text { Mean } \\
\pm \text { SD }\end{array}$ & $5 \pm 2$ & $\begin{array}{c}17 \mathrm{M}, \\
9 \mathrm{~F}\end{array}$ & $16.5 \pm 3$ & 10C,15T,1L & $10.8 \pm 3$ & - & $2.7 \pm 1$ & $2.7 \pm 2$ \\
\hline P38 & 3 & $\mathrm{~F}$ & 15.0 & NA & 20 & - & - & - \\
\hline N150 & 4 & M & 15.9 & NA & 20 & - & - & - \\
\hline N133 & 4 & $\mathrm{M}$ & 18.0 & NA & 20 & - & - & - \\
\hline N130 & 5 & $\mathrm{~F}$ & 16.4 & NA & 20 & - & - & - \\
\hline N134 & 5 & $\mathrm{M}$ & 15.1 & NA & 20 & - & - & - \\
\hline N126 & 6 & $\mathrm{M}$ & 16.7 & NA & 20 & - & - & - \\
\hline N145 & 6 & $\mathrm{~F}$ & 9.2 & NA & 20 & - & - & - \\
\hline N110 & 7 & F & 18.0 & NA & 20 & - & - & - \\
\hline N147 & 9 & $\mathrm{~F}$ & 18.0 & NA & 20 & - & - & - \\
\hline N109 & 12 & M & 17.2 & NA & 20 & - & - & - \\
\hline $\begin{array}{l}\text { Mean } \\
\pm \text { SD }\end{array}$ & $6 \pm 2$ & $5 \mathrm{M}, 5 \mathrm{~F}$ & $15 \pm 2$ & NA & 20 & - & - & - \\
\hline
\end{tabular}

$\mathrm{BMI}=$ Body mass index, SATCo $=$ Segmental assessment of trunk control, $\mathrm{T}=$ thoracic, $\mathrm{C}=$ cervical, $\mathrm{L}=$ lumbar. AIS $=$ American spinal injury association impairment scale (If age $<7$ years, the injury level listed in medical records was reported).

\subsubsection{Trunk Control Assessment}

Trunk control was assessed using the SATCo test. Participants were tested in a seated position with arms and back unsupported on a bench with hip and knee both at $90^{\circ}$ of flexion with feet supported. Trunk control was examined with a therapist progressively changing the level of support from top at shoulder girdle and axilla to assess cervical (head) control, inferior-scapula (mid-thoracic), lower-ribs 
(lower thoracic), below-ribs (upper-lumbar), pelvis (lower-lumbar), and no-support, to measure full trunk control [22]. The pelvis was placed in a neutral position via manual support, except for no support level [20]. The testing for static control was successful if participants were able to maintain a stable and upright trunk for at least 5 seconds above the level of support without compensatory strategies such as neck or arm extension, trunk hyperextension (use of reflex activity or spasm) or excessive trunk lordosis [20]. If the participant exhibited compensatory strategies, the test allowed for correction, if compensation persisted, i.e., failed, the test ended, and the prior successful test score was reported as the final score and level.

\subsubsection{Surface Electromyography (EMG)}

During the SATCo test, EMG signals from trunk muscles were recorded bilaterally using wireless, pre-amplified bipolar electrodes (Cometa, Italy). Skin area over the muscle belly was cleaned with alcohol swabs and electrodes were placed on the following muscles: pectoralis major (PEC) at midclavicular line; external intercostal (INT) at 6th intercostal space on axillary line; rectus abdominus (RA) at umbilical level; external oblique (OB) at midaxillary level; thoracic paraspinal (PST) at T9-10 vertebral level; and lumbar paraspinal (PSL) at L4-5 vertebral level [23]. The EMG signals were sampled at $2000 \mathrm{~Hz}$ with a bandpass filter of 10-500 Hz. Root mean square (RMS) values of each trunk muscle activity acquired during SATCo performance and over a 5 second window were calculated.

\subsubsection{EMG Normalization}

Root mean square values of each muscle were calculated using the first SATCo level and used as the baseline level of muscle activation level for both the groups since participant's trunk and arms were fully supported. EMG signals were normalized by subtracting the baseline EMG from EMG signals recorded during progressive levels of SATCo. Therefore, the two groups were compared for rest of the levels.

\subsection{Statistical Analyses}

The continuous variables (age and BMI) were summarized using median with interquartile range (25th and 75th percentile). Categorical variables (sex and injury-level) were summarized using frequency count with associated percentage (Table 2). Each participant in the TD group scored 20/20 on SATCo test therefore, a one sample median test was used to compare the variable SATCo scores of participants in the SCI group to standard/fixed scores in the TD group. Normalized RMS values for each muscle at each SATCo level were presented as the median with interquartile range (Table 3). Values of the group with SCI and TD were compared with the Wilcoxon Rank Sum test for the central tendency. Statistical analyses were performed in SAS (SAS Institute, NC) and graphical displays were plotted in R.

Table 2. Summary of categorical variables of typically developing children and children with spinal cord injury.

\begin{tabular}{cccc}
\hline & SCI & TD & $P$ \\
\hline & $n=26$ & $N=10$ & \\
Median (IQR) & $5(3,6)$ & $5(4,7)$ & 0.35 \\
Median (IQR) & $15(15,17)$ & $16(15,18)$ & 0.54 \\
Female, $n(\%)$ & $9(35 \%)$ & $5(50 \%)$ & - \\
Male, $n(\%)$ & $17(65 \%)$ & $5(50 \%)$ & - \\
Cervical, $n(\%)$ & $10(38 \%)$ & - & - \\
Thoracic, $n(\%)$ & $15(58 \%)$ & - & - \\
Lumbar, $n(\%)$ & $1(4 \%)$ & - & - \\
\hline
\end{tabular}

$\mathrm{SCI}=$ Spinal cord injury, TD = Typically developing, IQR = Interquartile range $(\mathrm{min}, \mathrm{max})$. 
Table 3. Root mean square (RMS) values of trunk muscles during SATCo assessment in typically developing children and in children with spinal cord injury.

\begin{tabular}{|c|c|c|c|c|}
\hline & & SCI & TD & \\
\hline & & 26 & 10 & \\
\hline \multirow[t]{3}{*}{ Muscle } & Measurement & & & $p$-value \\
\hline & Axilla (median (IQR)) & $-5(-11,3)$ & $-1(-6,0)$ & 0.82 \\
\hline & Inferior scapula (median (IQR)) & $-1(-9,3)$ & $1(0,5)$ & 0.53 \\
\hline \multirow{6}{*}{ PEC } & Over lower ribs (median (IQR)) & $-2(-8,14)$ & $1(-1,2)$ & 0.80 \\
\hline & Below ribs (median (IQR)) & $11(6,30)$ & $0(-2,3)$ & $0.002 *$ \\
\hline & Pelvis (median (IQR)) & $15(-1,66)$ & $0(-4,2)$ & 0.23 \\
\hline & No support (median (IQR)) & $35(0,70)$ & $0(-4,1)$ & 0.11 \\
\hline & Axilla (median (IQR)) & $22(10,32)$ & $26(10,77)$ & 0.42 \\
\hline & Inferior scapula (median (IQR)) & $15(7,29)$ & $30(23,57)$ & $0.04 *$ \\
\hline \multirow{6}{*}{ INT } & Over lower ribs (median (IQR)) & $13(0,26)$ & $21(13,63)$ & 0.08 \\
\hline & Below ribs (median (IQR)) & $3(-6,36)$ & $20(5,73)$ & 0.12 \\
\hline & Pelvis (median (IQR)) & $15(-1,57)$ & $38(13,111)$ & 0.13 \\
\hline & No support (median (IQR)) & $11(3,26)$ & $24(10,37)$ & 0.39 \\
\hline & Axilla (median (IQR)) & $1(0,2)$ & $0(0,1)$ & 0.10 \\
\hline & Inferior scapula (median (IQR)) & $1(0,1)$ & $0(0,1)$ & 0.48 \\
\hline \multirow{6}{*}{ RA } & Over lower ribs (median (IQR)) & $0(0,3)$ & $0(0,1)$ & 0.19 \\
\hline & Below ribs (median (IQR)) & $3(0,4)$ & $0(0,0)$ & $0.02 *$ \\
\hline & Pelvis (median (IQR)) & $2(1,3)$ & $0(0,0)$ & 0.003 * \\
\hline & No support (median (IQR)) & $1(1,8)$ & $0(0,0)$ & $0.007 *$ \\
\hline & Axilla (median (IQR)) & $0(0,1)$ & $0(-3,0)$ & 0.08 \\
\hline & Inferior scapula (median (IQR)) & $0(0,1)$ & $0(-3,0)$ & 0.38 \\
\hline \multirow{6}{*}{ OB } & Over lower ribs (median (IQR)) & $0(-2,1)$ & $0(-1,1)$ & 0.69 \\
\hline & Below ribs (median (IQR)) & $2(-2,5)$ & $0(0,1)$ & 0.36 \\
\hline & Pelvis (median (IQR)) & $5(1,12)$ & $0(-1,1)$ & $0.002 *$ \\
\hline & No support (median (IQR)) & $7(7,21)$ & $0(-1,1)$ & $0.009 *$ \\
\hline & Axilla (median (IQR)) & $13(0,21)$ & $6(1,10)$ & 0.41 \\
\hline & Inferior scapula (median (IQR)) & $9(1,22)$ & $7(0,17)$ & 0.72 \\
\hline \multirow{6}{*}{ PST } & Over lower ribs (median (IQR)) & $13(5,29)$ & $4(-2,7)$ & $0.01 *$ \\
\hline & Below ribs (median (IQR)) & $20(15,24)$ & $1(-1,4)$ & $0.001 *$ \\
\hline & Pelvis (median (IQR)) & $18(4,33)$ & $3(0,6)$ & $0.03 *$ \\
\hline & No support (median (IQR)) & $18(15,35)$ & $7(2,14)$ & 0.06 \\
\hline & Axilla (median (IQR)) & $1(0,2)$ & $1(-1,5)$ & 0.77 \\
\hline & Inferior scapula (median (IQR)) & $0(0,4)$ & $5(1,15)$ & $0.03 *$ \\
\hline \multirow{4}{*}{ PSL } & Over lower ribs (median (IQR)) & $0(0,7)$ & $3(0,11)$ & 0.32 \\
\hline & Below ribs (median (IQR)) & $1(0,10)$ & $2(0,11)$ & 0.67 \\
\hline & Pelvis (median (IQR)) & $4(1,8)$ & $0(-1,2)$ & 0.07 \\
\hline & No support (median (IQR)) & $7(7,9)$ & $1(0,3)$ & $0.004 *$ \\
\hline
\end{tabular}

$\mathrm{SCI}=$ Spinal cord injury, TD = Typically developing, $\mathrm{PEC}=$ Pectoralis major, INT $=$ External intercostal, $\mathrm{RA}=$ Rectus abdominus, $\mathrm{OB}=$ External oblique, $\mathrm{PST}=$ Thoracic paraspinal, $\mathrm{PSL}=$ Lumbar paraspinal. $\mathrm{IQR}=$ Interquartile range (min, max), * Indicates significant differences in root mean square values between the two groups.

\section{Results}

\subsection{SATCo Scores Comparison between TD and Participants with SCI}

The SCI group scored significantly lower $(p<0.001)$ on the SATCo compared to the TD group. The SCI group demonstrated impaired trunk control on the SATCo: $10 \pm 3$ (Mean \pm SD) with no child demonstrating the highest score possible, 20. While every participant in the TD group scored, as anticipated, the full score of 20 for trunk control (Figure 1). 


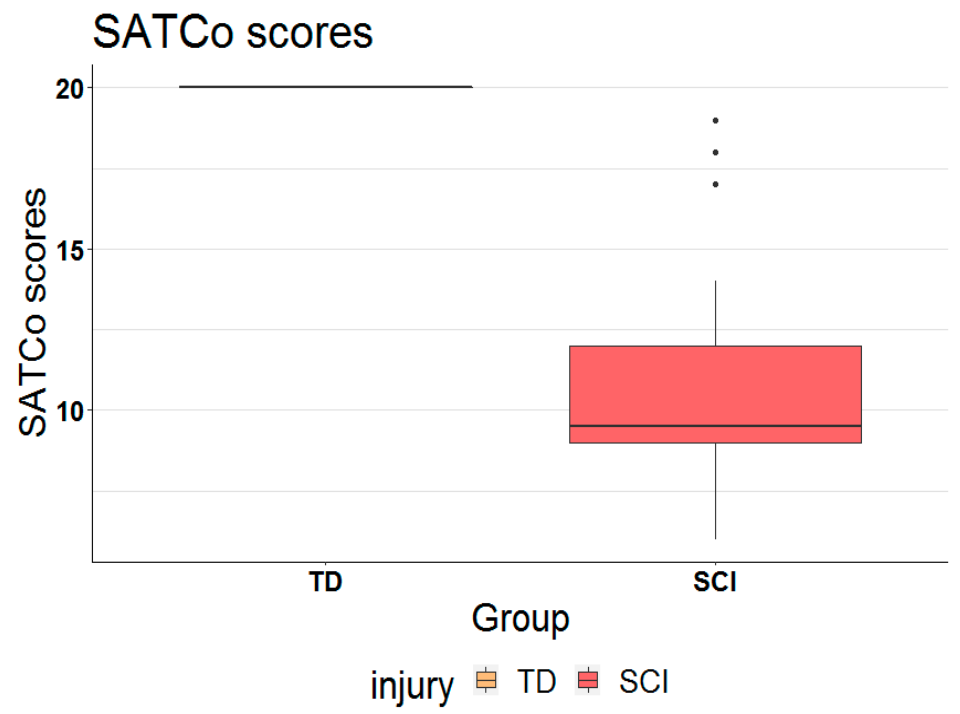

Figure 1. Comparison of Segmental assessment of trunk control (SATCo) scores between typically developing (TD) children and children with spinal cord injury (SCI). Note: every participant in the TD group scored 20/20 on SATCo test. The three dots $(\bullet \bullet \bullet)$ represents outliers outside $95 \%$ cutoff.

\subsection{EMG Muscle Activation between TD and Participants with SCI during Static SATCo Events}

Every participant in the TD group (20/20) completed all levels of SATCo test, whereas many participants in the SCI group (21/26) failed to complete all levels of SATCo testing. All 26 participants in the SCI group successfully completed axilla and scapular levels, 23/26 completed over-lower-ribs, 16/26 completed below-ribs, 12/26 completed pelvis, and only 5/26 completed no-support level. Therefore, the data analyses were presented only for participants in the SCI group who successfully performed static control at each support level compared to the performance by participants in the TD group at the same level (Figure 2).
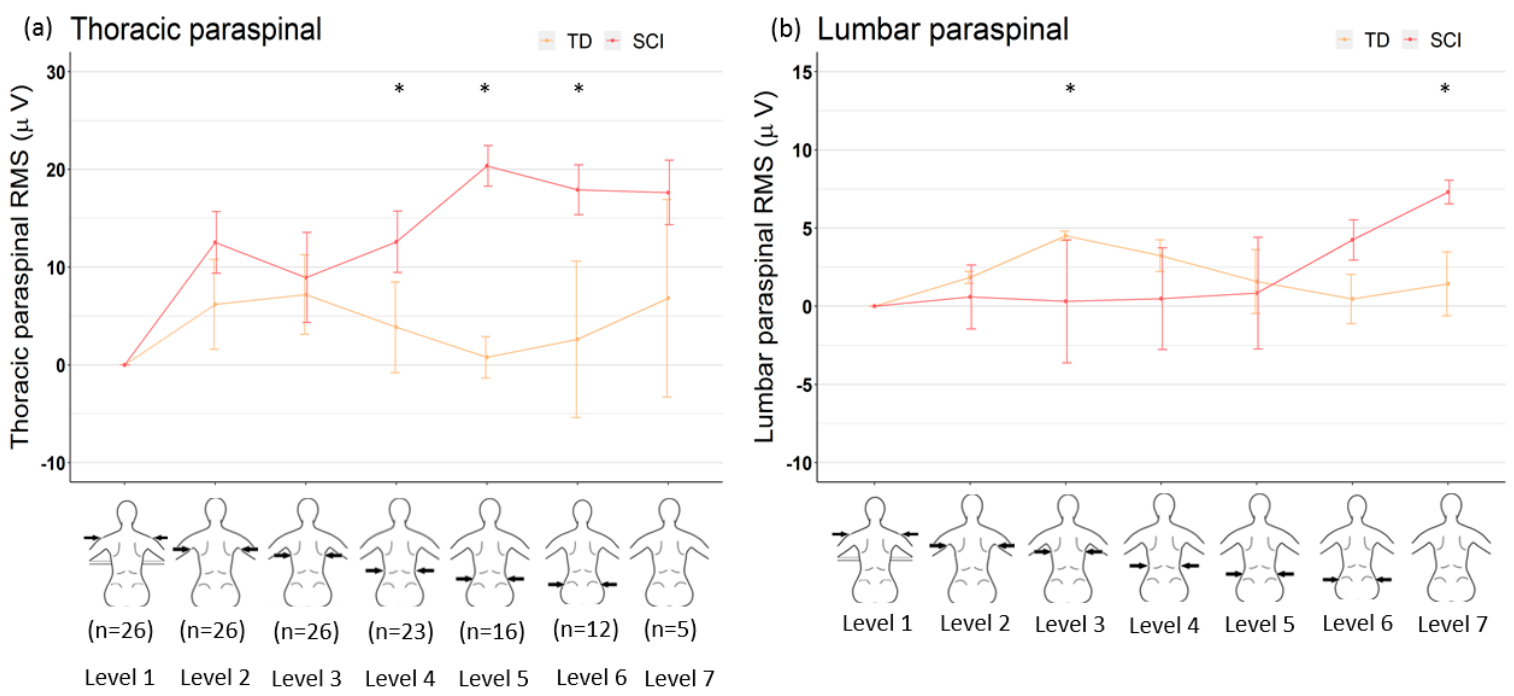

Figure 2. Cont. 
(c) Rectus abdominus

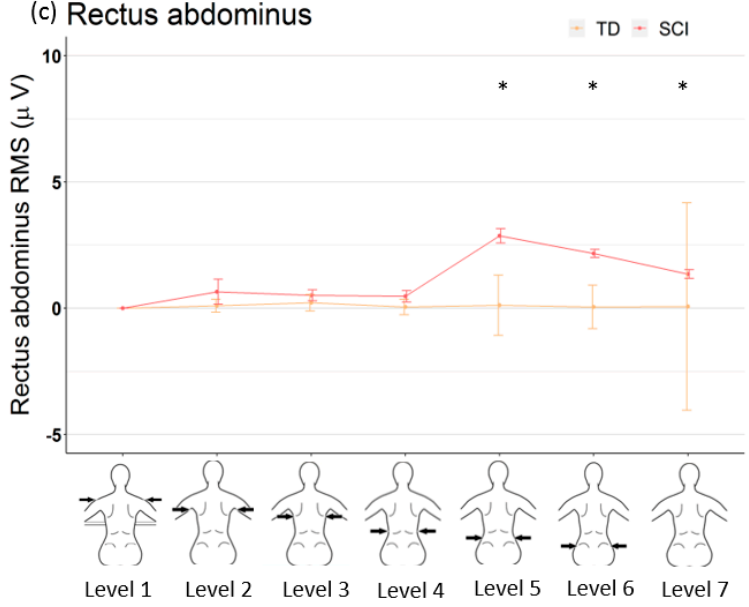

(e) Pectoralis major

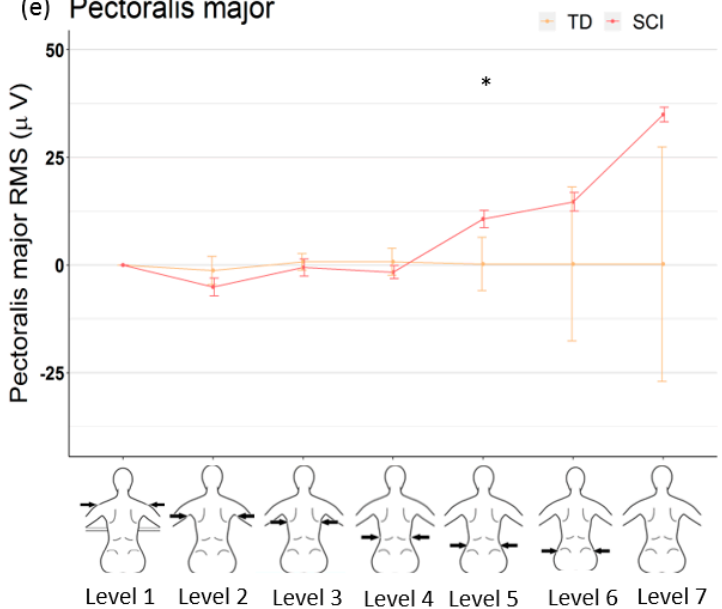

(d) External oblique

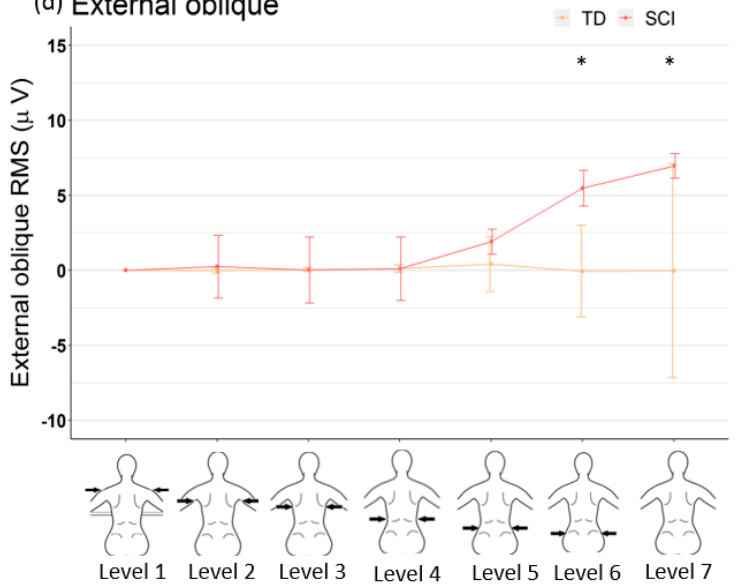

(f) External intercostal

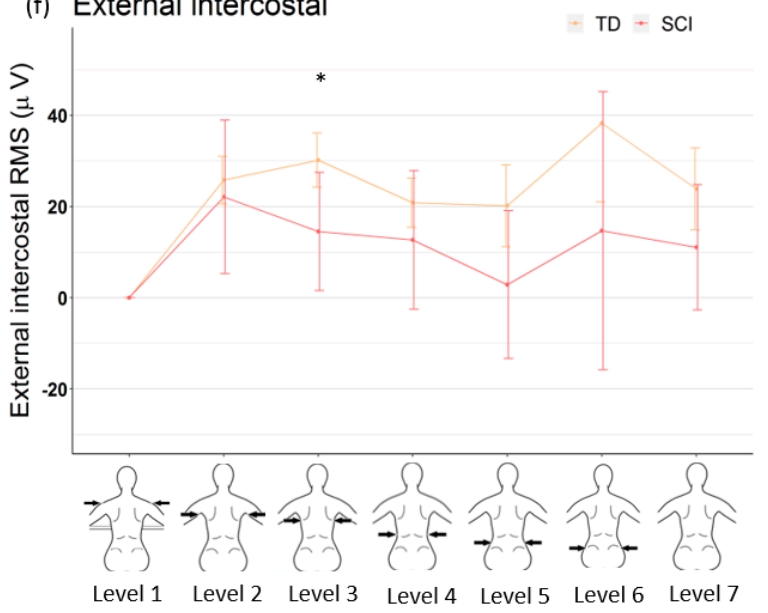

Figure 2. Comparison of trunk muscle activation during different SATCo support levels between children with spinal cord injury and typically developing children. Electromyography (EMG) data is represented as median of root mean square (RMS) values and standard error of median (SEM) bars of trunk muscles. (a) Thoracic paraspinal (PST), (b) Lumbar paraspinal (PSL), (c) Rectus abdominus (RA), (d) External oblique (OB), (e) Pectoralis major (PEC), and (f) External intercostal (INT) muscle.1 = shoulder level, $2=$ Axilla, $3=$ inferior scapula, $4=$ over lower ribs, $5=$ below ribs, $6=$ pelvis, $7=$ no support. ${ }^{*}$ Indicates significant differences in root mean square values between the two groups.

\subsection{Paraspinal Muscle Activation}

No significant differences in PST muscle activation was observed between the groups at axilla, inferior-scapula, and no-support levels (Figure 2a). Starting with the over-lower-ribs support level to each sequential level, the SCI group had a significantly higher PST muscle activation than the TD group (over-lower-ribs: $p=0.01$, below-ribs: $p=0.001$, and pelvis: $p=0.03$ ). No significant differences in PSL muscle activation was observed between the two groups at axilla, over-lower-ribs, below-ribs, and pelvis level (Figure 2b). However, the SCI group produced significantly lower EMG magnitude at inferior-scapula $(p=0.03)$ and significantly higher EMG magnitude at no-support $(p=0.004)$ level compared to the TD group (Table 3).

\subsection{Abdominal Wall Muscles}

For the first three levels, i.e., axilla to over-lower-ribs, RA muscle activation was not significantly different between the two groups. From below-ribs to each sequential level, the SCI group had significantly higher RA muscle activation than the TD group (below-ribs: $p=0.02$, pelvis: $p=0.003$, and no-support: $p=0.007$ ) (Figure 2c). For the first four levels, i.e., axilla to below-ribs, no significant 
differences in $\mathrm{OB}$ muscle activation was found between the two groups (Figure 2d). For the last two levels, pelvis and no-support, the SCI group produced significantly higher OB muscle activation than the TD group (pelvis: $p=0.002$ and no-support: $p=0.009$ ).

\subsection{Upper Thorax Muscles}

A significantly higher PEC muscle activation $(p<0.001)$ was produced in the SCI group at below-ribs compared to the TD group (Figure 2e). The INT muscle activation only at the inferior-scapula level was significantly higher $(p=0.04)$ in the TD group compared to the SCI group (Figure 2f).

\section{Discussion}

The main findings of this study were, first, that children with SCI, expectedly, demonstrated significant impairment in trunk control assessed by the SATCo. Second, unexpectedly, children with SCI activated trunk muscles not only above the injury level, but also below the injury level.

Each child in the TD group completed the test with highest possible score (total of 20). While, $1 / 26$ achieved the highest score of 19 and 2/26 achieved highest score of 18 . In the SCI group, only 5 out of 26 children completed the no-support static level of SATCo successfully. This significant difference in SATCo scores in children with SCI was expected due to weakness or paralysis of trunk muscles resulting in the inability to sit upright or sit with impaired posture when challenged, yet segmental support was provided [20]. In parallel to the assessment of trunk control, we examined and compared trunk muscle activation using EMG in children with SCI to TD children. EMG assessment in both, TD and SCI groups, allowed objective quantification of trunk muscle activity with each level of support. We found that children in both the groups, produced activation in all six trunk muscles, recorded above and below the level of support (Figure 2). In addition, children in the SCI group, unexpectedly, produced higher activation in trunk muscles below injury level (Figure 2). This quantification of trunk muscle activity using EMG is of significance, as it allows characterization of the extent of sensorimotor function below injury level which may persist following SCI in children (Figure 3).

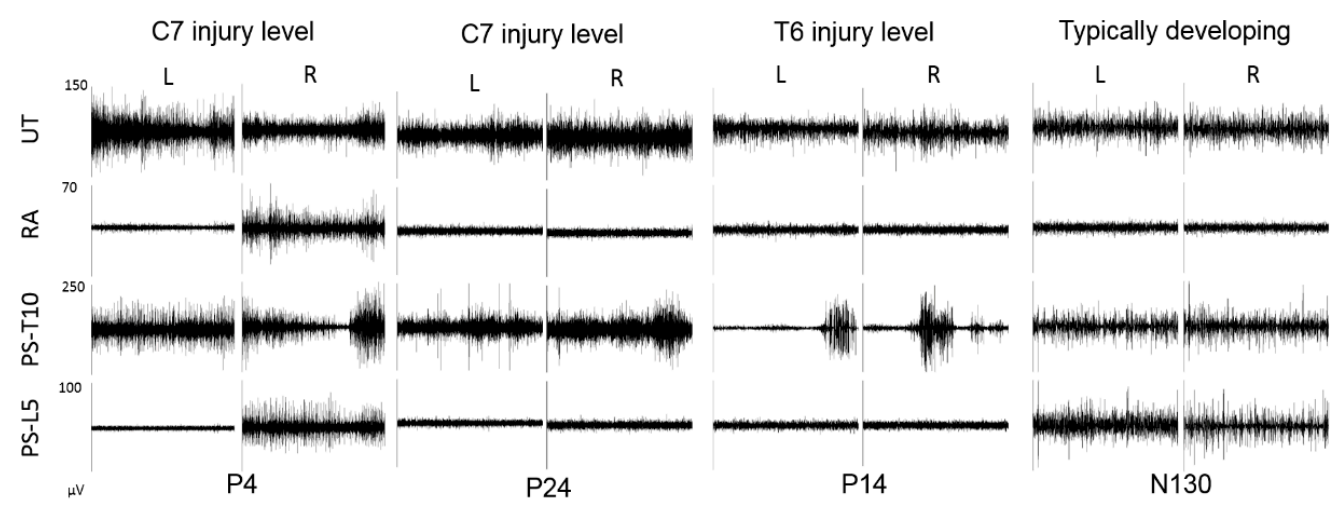

Figure 3. Trunk muscle activation in one typically developing (TD) child and three children with spinal cord injury (SCI) during SATCo test with over lower ribs support level. Note: activation of paraspinal muscles in children with SCI. UT = upper trapezius; RA = rectus abdominus; PS-T10 = thoracic paraspinal; PS-L5 = lumbar paraspinal muscle.

\subsection{Activity Level in Paraspinal Muscles}

Erector spinae muscles are primary extensors of the trunk and considered postural muscles, as they are active during sitting, standing upright and during trunk extension tasks [24]. We found that children in both groups, TD and SCI produced activation in both lumbar and thoracic paraspinal muscles at every support level during SATCo. However, the activity level in the two groups was significantly different with children in the SCI group producing higher activation with decreasing level of support from over-lower-ribs to no-support level. Interestingly, all children in the SCI group 
produced activation in thoracic paraspinal muscles irrespective of injury level (Figure 2a). In addition, several children with SCI also produced activation in lumbar paraspinal muscle below injury level. However, the muscle activity was significantly higher only for those successfully performing the static, no-support level (Figure 2b). Thoracic-paraspinal muscle activity recorded at T10-T11 spinal level and lumbar at L4-L5 vertebral level corresponds to T11-T12 and L4-L5 spinal segment, respectively [25]. In the SCI group, 25/26 children were injured at or above T12 level and 1/26 was injured at L1 level (Table 1). This increased muscle activation in the SCI group indicates the potential to recruit available erector spinae muscle to promote upright sitting. While only 5 children in the SCI group successfully completed the last level of SATCo, each child produced activation in paraspinal muscles (Figure 3). These findings support the presence of residual motor activity below the injury level. Additional factors, such as contraction of antagonistic muscle, spasm or reflexive activity may facilitate/influence activation of trunk muscles below the injury level [8]. However, in the current study, we excluded any postural attempts that may have resulted due to spasms or compensation. Recent work from our laboratory quantified pattern and activity of trunk and lower limb muscles during a sit-up task in children with SCI and reported similar findings with 24 children with SCI produced activation in muscles above and below injury levels. Though the task was performed in supine position [26]. Studies in adults with SCI reported similar results, where individuals produced activation in trunk muscles, specifically in paraspinal muscle at T5 and T12, below injury level $[8,16]$. In our study, in addition to the presence of activation in paraspinal muscles below injury level, we also observed that the activation was significantly higher than the TD children.

\subsection{Activity Level in Abdominal Wall Muscles}

Numerous studies have shown that abdominal wall muscles, rectus-abdominus and external-oblique muscles, contribute to the stability of the trunk and in preparation for limb movements $[27,28]$. Interestingly, children with SCI produced significantly higher activation in the RA muscle as the support level was moved from below-ribs to no-support (Figure 2c). Whereas OB muscle activation was significantly higher in the SCI group for last two support levels, i.e., pelvis and no-support. However, only $12 / 26$ and 5/26 children in the SCI group were tested for these two levels, respectively. This activation in both, abdominal wall and thoracic paraspinals increases trunk stiffness to provide stability for an upright posture. Compared to thoracic paraspinal muscles, abdominal wall muscles are innervated by lower spinal segments, ranging from T7-L1 [29]. The higher activation of paraspinal and abdominal wall muscles above and below injury levels in children with SCI reflects the residual supraspinal influence on spinal motor neurons supplying these postural muscles. The identification of residual or preserved muscle activity below injury level in all participants with SCI regardless of the level, etiology or severity of injury provides a scientific basis for refining the current clinical practices and expectation for neuromuscular capacity and trunk control in children with SCI.

\subsection{Activity Level in Upper Chest Muscles}

Pectoralis and external intercostal muscles are considered to have dual function for posture control and respiration [30,31]. During various levels of support, children in both groups, produced activation in these two muscles. Both groups produced the same level of activation for all, except at below-ribs support level, where children in the SCI group produced higher activation in the pectoralis muscle than the TD group. This increased muscle activation may be due to forward arm movement during the test.

SCI-induced trunk muscle paralysis during rapid skeletal growth significantly hastens the onset and progression of scoliosis with nearly $100 \%$ of children injured before 10 developing scoliosis and $65 \%$ requiring surgery $[10,11]$. Given these significant functional impairments with added risk for developing scoliosis, understanding the effect of SCI on trunk muscles should be one of the primary focuses in rehabilitation research to change the trajectory of outcomes in children with SCI. Studies in adults with chronic SCI have shown evidence of muscular adaptations ranging from change in fiber composition, contractile properties to more fatigable. Pathological changes, such as muscle asymmetry 
and fiber composition in paraspinal muscles are thought to contribute to the progression of scoliosis in children with muscular dystrophies and adolescent idiopathic scoliosis. However, in contrast to cell-based therapeutic approaches [32], we propose that therapists may take advantage of the residual activation of trunk muscles below the lesion in children with SCI to improve posture control. We are in early stages of understanding the muscle contribution to development of scoliosis in children with SCI. Further research in children with SCI is warranted to explore and identify specific musculoskeletal adaptions and optimal therapeutic strategies to influence these adaptations. Therefore, assessment and quantification of trunk muscle activity using EMG is a critical means to understand the involvement and severity of muscle impairment after pediatric-onset SCI. In this study, we found that despite the obvious impairment in trunk control based on SATCo scores, children with SCI had activation of trunk muscles above and below the injury level during SATCo test. This observation has significant clinical implications as it can inform the development of evidence-based therapies for children with SCI capitalizing on a substantial amount of remaining neuromuscular capacity. The results of this study also support the need to revisit the current gold standard classification system assessing trunk muscle impairment based on the assessment of sensory function. In this study, we did not control for injury demographics such as etiology of injury, time since injury, severity of injury, intervention received (if any), and length of intervention received. These factors may have influenced the EMG activity observed during this study. Information on injury site and severity using neuroimaging techniques may be relevant to the presence of residual muscle activity below the lesion. In the current study, EMG activity was collected only during steady state control; however, anticipatory and reactive control testing may provide greater postural control challenge and thus additional knowledge on underlying postural muscle activity post SCI.

\section{Conclusions}

In children with SCI, activation of trunk muscles above and below injury, irrespective of injury level is indicative of residual or preserved supraspinal influence on spinal motor circuitry supplying these postural muscles. The evidence of this residual muscle activation below the injury level may provide opportunities to quantify and utilize this activation to promote upright sitting and balance required for functional activities in the pediatric population.

Author Contributions: Conceptualization, G.S. and A.B.; methodology, G.S., S.A., B.U., and A.B.; software, G.S., B.U., and S.A.; validation, G.S., B.U., and A.B.; formal analysis, G.S. and B.U.; investigation, G.S.; resources, A.B., S.A., and B.U.; data curation, G.S. and A.B.; writing—original draft preparation, G.S. and A.B.; writing-review and editing, A.B., B.U., and S.A.; visualization, G.S. and A.B.; supervision, A.B.; project administration, G.S., and A.B.; funding acquisition, A.B. All authors have read and agreed to the published version of the manuscript.

Funding: The work of this study was supported by the Kosair Charities (GB141540).

Acknowledgments: The authors have stated no conflict of interest. The authors express their gratitude to Laura Mendez, Nicolas Foster, Luis Alvarado, Anastasia Keller, Lisa Clayton, Molly King, Micah Harlow, Parth Parikh, Thomas Machine, Ramy Emam, and Kathryn Lucas for their support, as well as all therapists of the Pediatric Neurorecovery Program at Frazier Rehab Institute and to Kosair Charities Center for Pediatric Neurorecovery, Kentucky Spinal Cord Injury Research Center, the University of Louisville.

Conflicts of Interest: The authors declare no conflict of interest.

\section{References}

1. Potten, Y.J.M.; Seelen, H.A.M.; Drukker, J.; Reulen, J.P.H.; Drost, M.R. Postural muscle responses in the spinal cord injured persons during forward reaching. Ergonomics 1999, 42, 1200-1215. [CrossRef]

2. Ceccato, J.-C.; De Sèze, M.; Azevedo, C.; Cazalets, J.-R. Comparison of Trunk Activity during Gait Initiation and Walking in Humans. PLoS ONE 2009, 4, e8193. [CrossRef] [PubMed]

3. Gauthier, C.; Gagnon, D.H.; Jacquemin, G.; Duclos, C.; Masani, K.; Popovic, M.R. Which trunk inclination directions best predict multidirectional-seated limits of stability among individuals with spinal cord injury? J. Spinal Cord Med. 2012, 35, 343-350. [CrossRef] 
4. Van der Fits, I.B.M.; Otten, E.; Klip, A.W.J.; Van Eykern, L.A.; Hadders-Algra, M. The development of postural adjustments during reaching in 6- to 18-month-old infants. Exp. Brain Res. 1999, 126, 517-528. [CrossRef] [PubMed]

5. Hadders-Algra, M.; Brogren, E.; Forssberg, H. Postural adjustments during sitting at preschool age: Presence of a transient toddling phase. Dev. Med. Child Neurol. 2008, 40, 436-447. [CrossRef] [PubMed]

6. Rachwani, J.; Santamaría, V.; Saavedra, S.L.; Woollacott, M.H. The development of trunk control and its relation to reaching in infancy: A longitudinal study. Front. Hum. Neurosci. 2015, 9, 94. [CrossRef] [PubMed]

7. Bertenthal, B.; Von Hofsten, C. Eye, Head and Trunk Control: The Foundation for Manual Development. Neurosci. Biobehav. Rev. 1998, 22, 515-520. [CrossRef]

8. Bjerkefors, A.; Carpenter, M.; Cresswell, A.; Thorstensson, A.; Cresswell, A.G. Trunk muscle activation in a person with clinically complete thoracic spinal cord injury. J. Rehabil. Med. 2009, 41, 390-392. [CrossRef]

9. Bolin, I.; Bodin, P.; Kreuter, M. Sitting position-Posture and performance in C5-C6 tetraplegia. Spinal Cord 2000, 38, 425-434. [CrossRef]

10. Kulshrestha, R.; Kuiper, J.H.; Masri, W.E.; Chowdhury, J.R.; Kaur, S.; Kumar, N.; Lalam, R.; Osman, A.E. Scoliosis in paediatric onset spinal cord injuries. Spinal Cord 2020, 58,711-715. [CrossRef]

11. Powell, A.J.; Davidson, L. Pediatric Spinal Cord Injury: A Review by Organ System. Phys. Med. Rehabil. Clin. N. Am. 2015, 26, 109-132. [CrossRef] [PubMed]

12. Kirshblum, S.; Burns, S.P.; Biering-Sorensen, F.; Donovan, W.; Graves, D.E.; Jha, A.; Johansen, M.; Jones, L.; Krassioukov, A.; Mulcahey, M.; et al. International standards for neurological classification of spinal cord injury (Revised 2011). J. Spinal Cord Med. 2011, 34, 535-546. [CrossRef] [PubMed]

13. Chafetz, R.S.; Gaughan, J.P.; Vogel, L.C.; Betz, R.; Mulcahey, M. The International Standards for Neurological Classification of Spinal Cord Injury: Intra-Rater Agreement of Total Motor and Sensory Scores in the Pediatric Population. J. Spinal Cord Med. 2009, 32, 157-161. [CrossRef] [PubMed]

14. Parent, S.; Mac-Thiong, J.-M.; Roy-Beaudry, M.; Sosa, J.F.; Labelle, H. Spinal Cord Injury in the Pediatric Population: A Systematic Review of the Literature. J. Neurotrauma 2011, 28, 1515-1524. [CrossRef] [PubMed]

15. Mulcahey, M.J.; Gaughan, J.; Betz, R.R.; Johansen, K.J. The International Standards for Neurological Classification of Spinal Cord Injury: Reliability of data when applied to children and youths. Spinal Cord 2007, 45, 452-459. [CrossRef] [PubMed]

16. Mitchell, M.D.; Yarossi, M.B.; Pierce, D.N.; Garbarini, E.L.; Forrest, G.F. Reliability of surface EMG as an assessment tool for trunk activity and potential to determine neurorecovery in SCI. Spinal Cord 2014, 53, 368-374. [CrossRef]

17. Verheyden, G.; Nieuwboer, A.; Mertin, J.; Preger, R.; Kiekens, C.; De Weerdt, W. The Trunk Impairment Scale: A new tool to measure motor impairment of the trunk after stroke. Clin. Rehabil. 2004, 18, 326-334. [CrossRef]

18. Heyrman, L.; Desloovere, K.; Molenaers, G.; Verheyden, G.; Klingels, K.; Monbaliu, E.; Feys, H. Clinical characteristics of impaired trunk control in children with spastic cerebral palsy. Res. Dev. Disabil. 2013, 34, 327-334. [CrossRef]

19. Saavedra, S.L.; Woollacott, M.H. Segmental Contributions to Trunk Control in Children With Moderate-to-Severe Cerebral Palsy. Arch. Phys. Med. Rehabil. 2015, 96, 1088-1097. [CrossRef]

20. Argetsinger, L.C.; Trimble, S.A.; Roberts, M.T.; Thompson, J.E.; Ugiliweneza, B.; Behrman, A.L. Sensitivity to change and responsiveness of the Segmental Assessment of Trunk Control (SATCo) in children with spinal cord injury. Dev. Neurorehabilit. 2018, 22, 260-271. [CrossRef]

21. Hansen, L.; Erhardsen, K.T.; Bencke, J.; Magnusson, S.P.; Curtis, D.J. The Reliability of the Segmental Assessment of Trunk Control (SATCo) in Children with Cerebral Palsy. Phys. Occup. Ther. Pediatr. 2017, 38, 291-304. [CrossRef] [PubMed]

22. Butler, P.B.; Saavedra, S.; Sofranac, M.; Jarvis, S.E.; Woollacott, M.H. Refinement, Reliability, and Validity of the Segmental Assessment of Trunk Control. Pediatr. Phys. Ther. 2010, 22, 246-257. [CrossRef] [PubMed]

23. Aslan, S.C.; Chopra, M.K.; McKay, W.B.; Folz, R.J.; Ovechkin, A.V. Evaluation of Respiratory Muscle Activation Using Respiratory Motor Control Assessment (RMCA) in Individuals with Chronic Spinal Cord Injury. J. Vis. Exp. 2013, 2013. [CrossRef] [PubMed]

24. Floyd, W.F.; Silver, P.H.S. The function of the erectores spinae muscles in certain movements and postures in man. J. Physiol. 1955, 129, 184-203. [CrossRef] 
25. Kayalioglu, G. Chapter 4-The Spinal Nerves. In The Spinal Cord; Watson, C., Paxinos, G., Kayalioglu, G., Eds.; Academic Press: San Diego, CA, USA, 2009; pp. 37-56.

26. Atkinson, D.A.; Mendez, L.; Goodrich, N.; Aslan, S.C.; Ugiliweneza, B.; Behrman, A.L. Muscle Activation Patterns During Movement Attempts in Children With Acquired Spinal Cord Injury: Neurophysiological Assessment of Residual Motor Function Below the Level of Lesion. Front. Neurol. 2019, 10, 1295. [CrossRef] [PubMed]

27. Urquhart, D.M.; Hodges, P.W.; Story, I.H. Postural activity of the abdominal muscles varies between regions of these muscles and between body positions. Gait Posture 2005, 22, 295-301. [CrossRef] [PubMed]

28. Hodges, P.W.; Richardson, C.A. Contraction of the Abdominal Muscles Associated With Movement of the Lower Limb. Phys. Ther. 1997, 77, 132-142. [CrossRef]

29. Stecco, C.; Azzena, G.P.; Macchi, V.; Porzionato, A.; Behr, A.U.; Rambaldo, A.; Tiengo, C.; De Caro, R. Rectus abdominis muscle innervation: An anatomical study with surgical implications in diep flap harvesting. Surg. Radiol. Anat. 2017, 40, 865-872. [CrossRef]

30. Bakkum, B.W.; Cramer, G.D. Chapter 4-Muscles That Influence the Spine. In Clinical Anatomy of the Spine, Spinal Cord, and Ans, 3rd ed.; Cramer, G.D., Darby, S.A., Eds.; Mosby: Saint Louis, MO, USA, 2014; pp. 98-134.

31. Hudson, A.L.; Butler, J.E.; Gandevia, S.C.; De Troyer, A. Interplay Between the Inspiratory and Postural Functions of the Human Parasternal Intercostal Muscles. J. Neurophysiol. 2010, 103, 1622-1629. [CrossRef]

32. Brzoska, E.; Kalkowski, L.; Kowalski, K.; Michalski, P.; Kowalczyk, P.; Mierzejewski, B.; Walczak, P.; Ciemerych, M.A.; Janowski, M. Muscular Contribution to Adolescent Idiopathic Scoliosis from the Perspective of Stem Cell-Based Regenerative Medicine. Stem Cells Dev. 2019, 28, 1059-1077. [CrossRef]

Publisher's Note: MDPI stays neutral with regard to jurisdictional claims in published maps and institutional affiliations. 